\title{
ALTERAÇÕES METABÓLICAS DO PERIPARTO DE BOVINOS: IMPLICAÇÕES NA IMUNIDADE, DOENÇAS UTERINAS E FERTILIDADE
}

\author{
METABOLIC CHANGES IN BOVINE PERIPARTUM: \\ IMMUNITY IMPLICATIONS, UTERINE DISEASES AND FERTILITY \\ João Paulo Elsen Saut ${ }^{1 \oplus}$, Carla Cristian Campos $^{2}{ }^{\circledR}$, \\ Layane Queiroz Magalhães $^{1 \oplus}$, Luisa Cunha Carneiro $^{3}{ }^{\circledR}$, Ricarda Maria dos Santos ${ }^{1} \odot$
}

\section{RESUMO}

Faculdade de Medicina Veterinária (FAMEV), Universidade Federal de Uberlândia (UFU), Uberlândia, Minas Gerais, Brasil.

Centro Universitário Una (UNA), Uberlândia, Minas Gerais, Brasil.

Departamento de Reprodução Animal (VRA), Laboratório de Ensino e Pesquisa em Patologia da Reprodução (LEPPaR), Centro de Biotecnologia em Reprodução Animal (CBRA), Faculdade de Medicina Veterinária e Zootecnia (FMVZ), Universidade de São Paulo (USP), Pirassununga, São Paulo, Brasil.

Revista Brasileira de Buiatria Enfermidades Metabólicas, Volume 2, Número 4, 2021

ISSN 2763-955X

DOI:10.4322/2763-955X.2021.013

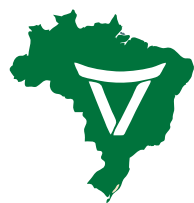

Associação Brasileira de Buiatria
Estudos relacionados aos efeitos das alterações metabólicas no periparto e suas implicações na imunidade, saúde uterina e fertilidade têm sido muito explorados. No entanto, apesar de muito já ter sido descrito, essas relações ainda não estão claramente elucidadas. Desta forma, o objetivo desta revisão é explorar as relações entre metabolismo, imunidade e fertilidade no periparto de bovinos. O período compreendido entre o final de gestação e o início da lactação é o momento de maior desafio para a vaca leiteira, já que neste intervalo ocorrem inúmeras mudanças fisiológicas, metabólicas e hormonais que afetam a saúde, a produtividade e o desempenho reprodutivo. As enfermidades uterinas podem acometer cerca de $40 \%$ das vacas leiteiras no pósparto, promovendo transtornos na saúde e bem-estar. Apesar de ocorrer a cura clínica dos animais acometidos por essas patologias, a eficiência reprodutiva não é totalmente reestabelecida durante a lactação, resultando em atraso no retorno à ciclicidade, redução das taxas de concepção ao primeiro serviço, aumento do intervalo de partos, e ainda, são responsáveis pelas principais causas de subfertilidade e infertilidade de rebanhos leiteiros, que levam ao descarte prematuro dos animais.

Palavras-chave: balanço energético negativo, cetose, hipocalcemia, período de transição, periparto.

\section{ABSTRACT}

Researches that link the effects of metabolic changes in the peripartum and their implications in immunity, uterine health and fertility have been extensively explored. However, the relationship between these factors is not yet well defined. Based on this, the aim of this review is to explore the association between metabolism, immunity, and fertility in cows during the peripartum period. It's well established that the period between the end of pregnancy and the beginning of lactation is the most challenging for dairy cows, since in this interval, there are numerous physiological, metabolic, and hormonal changes that affect health, productivity, and reproductive performance. Uterine diseases can affect about $40 \%$ of dairy cows in the postpartum period, which consequently affect animal health and welfare. A clinical recover of the animals affected with these pathologies is observed, on the other hand, the reproductive efficiency is not fully reestablished during lactation, as a delay to return to ovarian cyclicity, low conception rates at first service and longer calving intervals are observed. Also, these diseases are responsible for the main causes of subfertility and infertility in dairy herds, subsequently increasing involuntary culling rate. 


\section{INTRODUÇÃO}

A maior parte das doenças que acometem as vacas leiteiras ocorre próxima ao parto e estão relacionadas à dificuldade em se adaptar às demandas nutricionais necessárias para a lactação. Esta situação pode resultar em um desbalanço fisiológico, o qual é definido como uma situação crítica em que os mecanismos de regulação são insuficientes para uma resposta otimizada do animal, predispondo a um complexo de problemas digestórios, metabólicos e infecciosos ${ }^{1}$.

Uma transição eficiente para a lactação é essencial para o sucesso das vacas leiteiras nos sistemas de produção ${ }^{2}$. Desta forma, é importante entender alguns conceitos relativos a esta fase, como periparto e período de transição. O periparto é o intervalo compreendido entre os dois meses antes e um mês após a parição, já o período de transição inclui um período menor, de três semanas antes do parto e as primeiras três semanas de lactação ${ }^{2,3}$ e é considerado o período de maior desafio, não só para a vaca leiteira, assim como para a maioria dos mamíferos. No entanto, ambos períodos estão associados a uma elevada incidência de doenças metabólicas, infecciosas e não-infecciosas. Entre estas doenças destacam-se a cetose, esteatose hepática, hipocalcemia, retenção de placenta, metrite, endometrite, deslocamento de abomaso, afecções podais e mastite ${ }^{1,4,5}$.

Em relação às doenças uterinas, a alta incidência durante esta fase é atribuída, em parte, à redução da função do sistema imune inato e ainda, de uma regulação deficiente da inflamação ${ }^{6}$. Ressalta-se que durante ou após o parto, todas as vacas são submetidas a um processo de contaminação bacteriana uterina que ocorre essencialmente de forma ascendente, isto é, do ambiente para o interior do lúmen uterino ${ }^{7}$. Apesar do útero possuir sua própria microbiota, a contaminação por bactérias durante o parto interfere no equilíbrio entre esses microrganismos e nas respostas imunes locais e sistêmicas. Estes fatores fazem com que, aproximadamente, metade das vacas leiteiras sejam diagnosticadas com alguma doença inflamatória do trato reprodutivo no pós-parto imediato ${ }^{8}$.

Esta revisão irá explorar eventos fisiológicos e patológicos que ocorrem no periparto de vacas leiteiras que podem interferir na imunidade, saúde uterina e fertilidade, e suas inter-relações. Para facilitar a leitura, o texto será estruturado em quatro seções:

\section{- Puerpério fisiológico;}

- Imunidade e alterações metabólicas no periparto;

- Doenças uterinas;

- Implicações na fertilidade de vacas leiteiras.

\section{PUERPÉRIO FISIOLÓGICO}

Após o parto, o objetivo maior da vaca leiteira é retomar à ciclicidade ovariana e a conceber o mais breve possível. Para que a vaca esteja apta ao manejo reprodutivo, a expulsão das membranas fetais deve ser imediata, seguida da involução uterina e do restabelecimento da atividade ovariana, havendo regeneração completa do endométrio e controle eficiente da contaminação bacteriana uterina (Tabela 1). Dessa forma, o puerpério fisiológico é o período entre o parto e a completa involução uterina, que ocorre, aproximadamente, até os quarenta dias em lactação (DEL) ${ }^{9}$.

No entanto, vários fatores podem atrasar o processo de involução uterina, como traumas durante o parto, principalmente distocias e auxílio ao parto ${ }^{11,12}$, retenção de placenta ${ }^{11,13}$, distúrbios metabólicos ${ }^{11,14-16}$, como cetose ${ }^{11,12}$ e a hipocalcemia ${ }^{17,18}$, além da contaminação bacteriana ascendente e pela via hematógena ${ }^{18,19}$. 
Tabela 1. Eventos relacionados ao puerpério fisiológico e os fatores que o definem.

Eventos do puerpério fisiológico

Expulsão das membranas fetais
Fatores relacionados
Maturação placentária;

Exanguinação do lado fetal da placenta;

Contrações uterinas;

Fatores relacionados.
Involução uterina

Retorno à ciclicidade

Regeneração endometrial
Redução física do volume uterino e cervical após o parto; Contrações uterinas;

Reposição da matriz extracelular;

Necrose e descamação das carúnculas;

Regeneração endometrial.
Restabelecimento da frequência de pulsação de $\mathrm{LH}$; Eixo hipotálamo, hipófise, ovário e útero.

Fonte: Sheldon ${ }^{10}$.

\section{IMUNIDADE E ALTERAÇÕES METABÓLICAS NO PERIPARTO}

\section{- Sistema imune em bovinos - Noções básicas}

O sistema imune é dividido em inato e adaptativo. O sistema imune inato é responsável pela primeira linha de defesa do hospedeiro que, após uma invasão microbiana, uma resposta imediata é estabelecida, enquanto, o sistema imune adaptativo é ativado mais tardiamente, cerca de quatro a sete dias após a infecção e induz uma imunidade específica de longa duração ${ }^{20}$.

Vários estudos sugerem que aproximadamente 95\% dos desafios infecciosos são resolvidos pela resposta do sistema imune por meio de ações coordenadas por vários fatores, entre eles:
- Limpeza e fagocitose da contaminação realizada pelas células polimorfonucleares (PMN), como os neutrófilos, indispensáveis para a ativação do sistema imune, e ainda, outras células como os macrófagos e células dendríticas;

- Fatores humorais (sistema complemento, lisozima);

- Citocinas (grupo de proteínas), que atraem as células de defesa do sistema imune para a área afetada, desenvolvendo uma inflamação local pela ativação de diferentes fatores celulares ${ }^{21}$.

As citocinas são consideradas essenciais na integração entre o metabolismo animal e a função imunológica ${ }^{22}$, havendo diversos estudos que relacionam algumas interleucinas, como a $1 \beta$ (IL-1 $\beta$ ) e 6 (IL-6) e o fator de necrose tumoral $\alpha$ (TNF- $\alpha$ ) com doenças metabólicas e infecciosas durante o periparto ${ }^{23-25}$.

Basicamente, após o início de uma resposta 
inflamatória, as células PMN se tornam o tipo celular predominante. Elas migram do sangue para o local de invasão onde estão os microrganismos por um processo chamado de quimiotaxia ${ }^{26}$. Uma vez que um patógeno é envolvido, as células PMN desenvolvem um papel oxidativo primordial (burst oxidativo) nos fagócitos $\operatorname{ativados}^{27}$ com o propósito de destruir o invasor. Se a infecção persistir, o sistema imunológico específico (adaptativo) deve ser acionado. Essa imunidade específica é baseada na produção de anticorpos pela ação de macrófagos e por células como os linfócitos T e B que reconhecerão os microrganismos específicos a fim de combater o processo infeccioso.

No processo da regulação do sistema imune durante o periparto, o fígado merece destaque por ser considerado um órgão vital na regulação das respostas imunológicas, além de desempenhar diversas funções no metabolismo de carboidratos, proteínas e lipídios, e na depuração de toxinas e patógenos ${ }^{28}$. Em relação à resposta imune, o fígado está envolvido de duas formas principais: (1) diante de um processo inflamatório ele irá responder a mediadores (citocinas próinflamatórias) produzidos por células imunes (resposta de fase aguda) através da liberação de proteínas de fase $\operatorname{aguda}^{29,30}$. Estas proteínas são moléculas imunes inatas, não específicas, e suas principais funções são restaurar a homeostase do processo biológico, além de serem consideradas marcadores de inflamação ${ }^{31}$. Entre elas destacam-se a haptoglobina e a amiloide sérica A, que participam do processo de recrutamento de células imunes para o local da infecção e (2) o fígado também pode reagir contra antígenos metabolizados podendo levar a danos ao tecido local ${ }^{28}$ (Figura 1 ).

Após o desenvolvimento de uma infecção

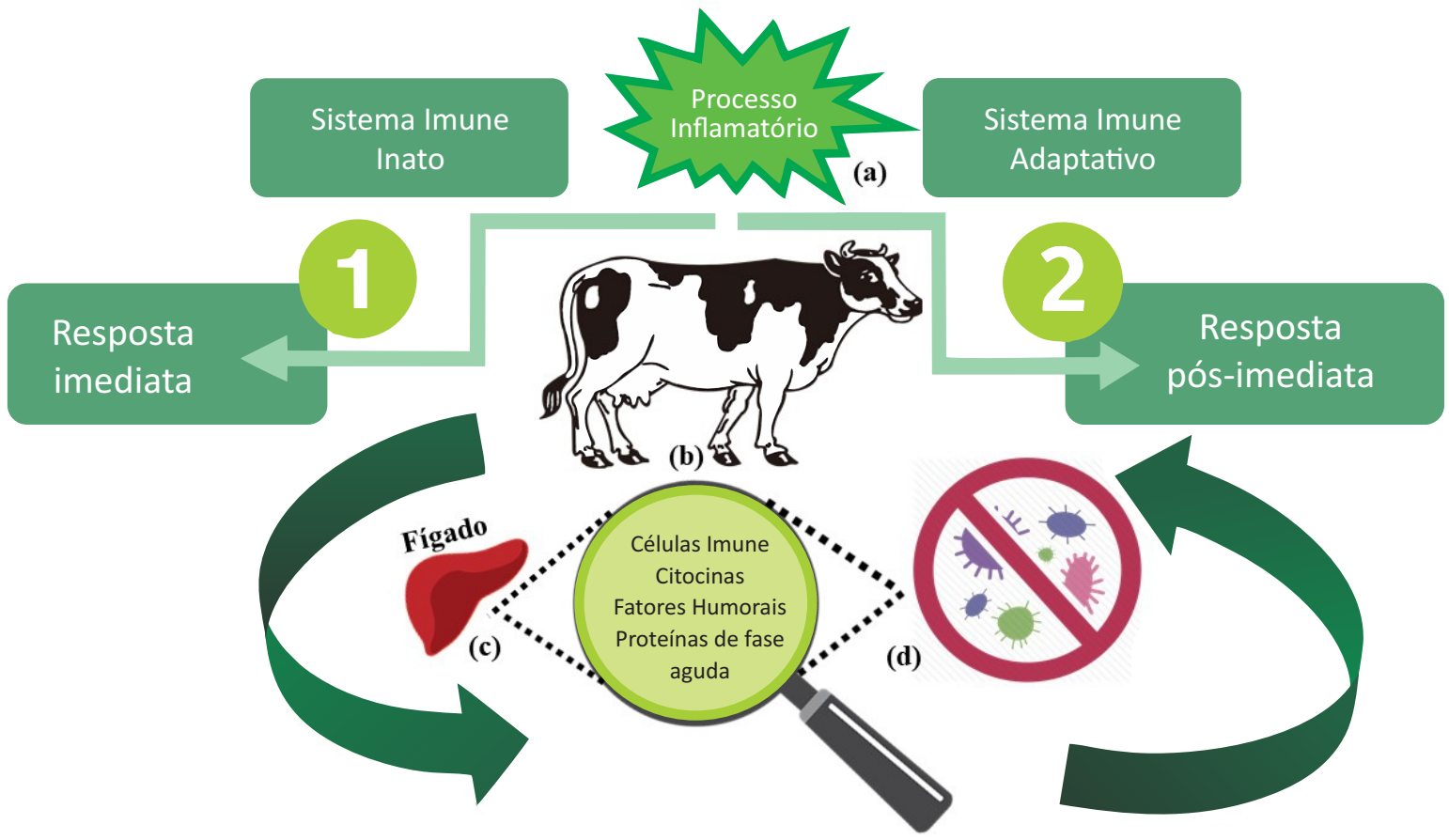

Figura 1. Esquema ilustrativo da resposta imune após um processo inflamatório. Em um processo inflamatório o sistema imune inato (1) é responsável pela primeira linha de defesa (resposta imediata), enquanto, o sistema imune adaptativo (2) é ativado mais tardiamente (resposta pós-imediata). (A) Após o início de uma resposta inflamatória, as células imunes migram do sangue para o local de invasão. (B) Outro ponto fundamental do sistema imune é a liberação de citocinas inflamatórias, essas, integram o metabolismo animal e a função imunológica. Caso a inflamação persista, o sistema imune adaptativo (baseado na produção de anticorpos) será ativado. (C) Ainda, em um processo inflamatório o fígado será o responsável pela liberação de proteínas de fase aguda que participam do processo de recrutamento de células imunes (D) para que esses fatores juntos combatam ao processo de inflamação. 
e/ou inflamação no hospedeiro, a ativação e migração de células de defesa para o local são etapas fundamentais para a imunidade inata e adaptativa. A importância da atividade das células PMN durante o periparto é primordial, porém, não pode ser exagerada porque essas células também estão envolvidas desde o período do parto (com a expulsão das membranas fetais) ${ }^{32}$ e serão a primeira linha de defesa do útero no pósparto $^{33}$.

Compreender o papel fundamental da resposta imunológica nas alterações metabólicas de vacas durante o periparto auxilia na explicação das ligações entre essas diversas condições. A ativação dos mecanismos de defesa locais e sistêmicos do hospedeiro induz a inflamação; além disso, mudanças significativas na expressão gênica ocorrem como uma adaptação às demandas da lactação, manutenção e rápida involução do útero ${ }^{34}$. Ainda, a fim de manter o equilíbrio da defesa animal, uma série de moléculas de sinalização são liberadas por células imunes ativadas, incluindo mediadores inflamatórios, como as citocinas e as proteínas de fase aguda ${ }^{35-37}$.

\section{- Efeito das doenças metabólicas no sistema imune inato de bovinos durante o periparto}

O periparto de vacas leiteiras é caracterizado por mudanças drásticas no metabolismo e nos mecanismos de defesa do hospedeiro e estão associados ao surgimento de diversas doenças ${ }^{1}$. O sistema imunológico desses animais já é desafiado desde o pré-parto e passa por inúmeras mudanças para que possa auxiliar o animal durante o parto e atuar como protetor dos processos infecciosos durante o pós-parto ${ }^{38}$.

O primeiro grande desafio do sistema imune de vacas leiteiras ocorre imediatamente após o nascimento do bezerro, momento em que as membranas fetais devem ser reconhecidas pelo sistema imunológico da vaca como um "corpo estranho" para a ativação das células imunológicas inatas e a expulsão das membranas fetais ${ }^{39}$. Porém, o sistema imunológico de 4 a $11 \%$ das vacas é incapaz de exercer esse reconhecimento e expelir adequadamente as membranas fetais. $\mathrm{O}$ segundo grande desafio do sistema imune é a transferência dessa proteção imunológica para os bezerros nas primeiras semanas de vida via colostro. Os níveis de imunoglobulinas durante o pós-parto devem se manter equilibrados tanto para proteger os animais de patógenos invasores quanto para gerar uma imunidade para seus descendentes, dessa forma, uma interrupção desse equilíbrio compromete a proteção imunológica das vacas leiteiras, principalmente durante o periparto ${ }^{38}$.

O desafio metabólico ao qual as vacas leiteiras são submetidas leva a um aumento da resposta inflamatória expressa pelas células imunológicas e aqueles animais que desenvolvem um processo inflamatório mais pronunciado, consequentemente, terão maior déficit de nutrientes e o surgimento de enfermidades metabóli$\operatorname{cas}^{40}$.

Hammon et al. $^{41}$ demonstraram que a redução do consumo de matéria seca durante o pré-parto reduz a atividade das células PMN durante o periparto, aumentando a probabilidade de doenças puerperais, principalmente, retenção de placenta e metrite. Consequentemente, elevada incidência dessas enfermidades são consideradas manifestações de um sistema imunológico com mau funcionamento ${ }^{42}$.

Diversos estudos já relataram a ligação entre doenças metabólicas e a resposta imune ${ }^{43,44}$. Durante o periparto, a falta de nutrientes e energia é comumente avaliada pela medição de marcadores de balanço energético negativo (BEN), como a concentração de ácidos graxos não esterificados (AGNE), corpos cetônicos como o beta-hidroxibutirato (BHB), bem como mensurações de glicose circulante, sendo assim, alguns estudos apontaram para os efeitos diretos desses marcadores na função do sistema imune ${ }^{40}$. Vacas em BEN apresentam baixa concentração plasmática de glicose, maiores concentrações de AGNE e um aumento de corpos 
cetônicos (aumento dos níveis de $\mathrm{BHB})^{5,45}$.

Ao relacionar as concentrações de AGNE com sistema imune animal, Kovác et al. ${ }^{46}$ sugeriram que sua maior concentração plasmática pode estar relacionada à ativação do sistema imunológico. Uma vez que a capacidade do fígado é limitada, metabólitos como AGNE, irão se acumular no sangue e, por conseguinte, causar vários efeitos adversos além da redução da ingestão de alimentos, como suprimir a resposta imunológica animal e diminuir o seu desempenho produtivo e reprodutivo ${ }^{47}$.

Concentrações elevadas de AGNE plasmático alteram a capacidade dos linfócitos de proliferar ou secretar fatores relacionados ao sistema imune como imunoglobulinas e interferons ${ }^{48}$, bem como a viabilidade e burst oxidativo das células $\mathrm{PMN}^{49}$. Ainda, os níveis elevados de AGNE plasmático predispõem para o desenvolvimento de esteatose hepática que, por sua vez, é um fator imunossupressor de vacas durante o periparto $^{50}$.

A disponibilidade de glicose está diretamente relacionada com a concentração de AGNE, sendo extremamente importante na função das células imunológicas, pois estimula a proliferação celular, diferenciação, sobrevivência e fagocitose. A baixa disponibilidade de glicose pode limitar a função imunológica e aumentar o risco de infecções durante o periparto. Dessa forma, uma captação eficiente de glicose pelas células do sistema imune é crítica para manter suas funções e provocar uma resposta de recuperação do hospedeiro aos patógenos invasores. Concentrações normais de glicose durante o periparto são fundamentais para a ação das células fagocíticas (macrófagos e PMN) para proliferação, sobrevivência e diferenciação, e a glicose ainda, é eleita pelas células imune como combustível metabólico preferido durante um processo inflamatório ${ }^{1}$.

Os leucócitos de vacas com hipoglicemia estão comprometidos durante o processo de migração para a defesa animal ${ }^{51}$. O BEN pós-parto acentuado, acompanhado por concentrações aumentadas de BHB, também foi associado a maiores riscos de doenças e alterações do sistema imune no periparto ${ }^{52-54}$. Dessa forma, vacas com cetose subclínica ou clínica possuem sua função imunológica prejudicada, aumentando assim o risco de mastite e outras doenças infecciosas durante o início da lactação. De acordo com Ingvartsen e Moyes ${ }^{1}$, os corpos cetônicos mostraram ter efeitos prejudiciais sobre os parâmetros imunológicos, como na quimiotaxia, no burst oxidativo, na produção de espécies reativas de oxigênio (EROs) e na fagocitose celular.

As demandas metabólicas associadas ao final da gestação, durante o parto e início da lactação aumentam a produção de $\mathrm{ERO}^{55}$. As células imunológicas são particularmente sensíveis ao estresse oxidativo, pois suas membranas contêm altas concentrações de ácidos graxos poli-insaturados (AGPI) que são muito suscetíveis à peroxidação e produzem grandes quantidades de EROs quando estimuladas e, como consequência, as EROs liberadas causam danos celulares aos tecidos ${ }^{56}$.

Outro metabólito essencial na regulação da resposta imune é o macromineral cálcio $(\mathrm{Ca})$. Ele é importante para a manutenção da função das células imunológicas e, vacas que experimentam uma diminuição nas concentrações sanguíneas (hipocalcemia clínica ou subclínica) estão predispostas a doenças infecciosas e inflamatórias durante o pós-parto. Uma baixa concentração de cálcio nas primeiras duas semanas pós-parto está associada à diminuição das funções dos neutrófilos ${ }^{57}$.

A hipocalcemia pode ser uma consequência de desafios ao sistema imunológico ${ }^{58}$. Embora as consequências desta doença metabólica não estejam totalmente estabelecidas, vacas hipocalcêmicas durante os primeiros três dias de lactação tiveram aumento marcante na mobilização de lipídios e uma diminuição da porcentagem de neutrófilos com atividades fagocíticas, e foram expostas a um risco muito maior de desenvol- 
ver metrite puerperal em comparação com vacas normocalcêmicas ${ }^{57}$.

Sendo assim, uma melhor compreensão molecular das vias inflamatórias, que desempenham um papel importante durante a função imunológica "normal", metabolismo e reprodução, pode melhorar nossa capacidade de prever e prevenir distúrbios em vacas no período de transição ${ }^{34}$.

\section{DOENÇAS UTERINAS NO PÓS-PARTO DE VACAS LEITEIRAS}

Sheldon e colaboradores ${ }^{59}$ descrevem uma mudança no perfil das doenças uterinas nos últimos cinquenta anos, já que no passado, poucas vacas desenvolviam tais enfermidades durante o pós-parto e, atualmente, sabe-se que a incidência destas doenças está em torno de 40\%. Este aumento, segundo os autores, coincidiu e pode estar associado à intensificação dos sistemas de criação dos rebanhos leiteiros e do aumento de cinco vezes mais da produção leiteira das vacas. Assim, os modelos intensivos atuais da bovinocultura leiteira, aliados ao melhoramento genético direcionado à alta produtividade, parecem aumentar ainda mais o desafio desses animais durante o pós-parto.

Cerca de 40 a 60\% das vacas leiteiras são acometidas por um ou mais distúrbios clínicos de saúde nos primeiros $60 \mathrm{DEL}^{60}$, e mais de $50 \%$ delas vivenciam, pelo menos um tipo de enfermidade subclínica nas primeiras semanas após o parto ${ }^{61}$. Ribeiro e Carvalho ${ }^{62}$ reportaram que aproximadamente um terço das vacas leiteiras têm pelo menos uma doença clínica (metrite, mastite, problema digestivo, respiratório ou claudicação) durante as primeiras três semanas de lactação. Como visto anteriormente, a alta incidência de doenças no período pós-parto surge como consequência da supressão da atividade imunológica, dos diversos desafios infecciosos aos quais as vacas estão expostas e das adaptações endócrinas e metabólicas requeridas pela lactação.

Desta forma, as doenças uterinas estão onipresentes no pós-parto de bovinos leiteiros com incidência, entre 30 e 60 DEL, de:

- Retenção de placenta: 2 a 5\%;

- Metrite: 25 a 40\%;

- Endometrite clínica:20\%;

- Endometrite subclínica ou citológica: 10 a $30 \%{ }^{63-68}$.

Portanto, a definição de critérios rigorosos para o diagnóstico, tratamento e prevenção destas enfermidades no pós-parto destes animais ainda continua sendo um desafio para as propriedades leiteiras ${ }^{68}$.

Há diferentes formas de definir estas enfermidades uterinas na literatura, sendo que uma delas leva em consideração a ordem cronológica, isto é, o momento em que estas ocorrem após o parto. A figura 2 mostra a sequência cronológica na ocorrência destas doenças em relação aos DEL. A retenção de placenta é a primeira desordem que o animal pode apresentar, sendo diagnosticada nas primeiras 24 horas após o par-

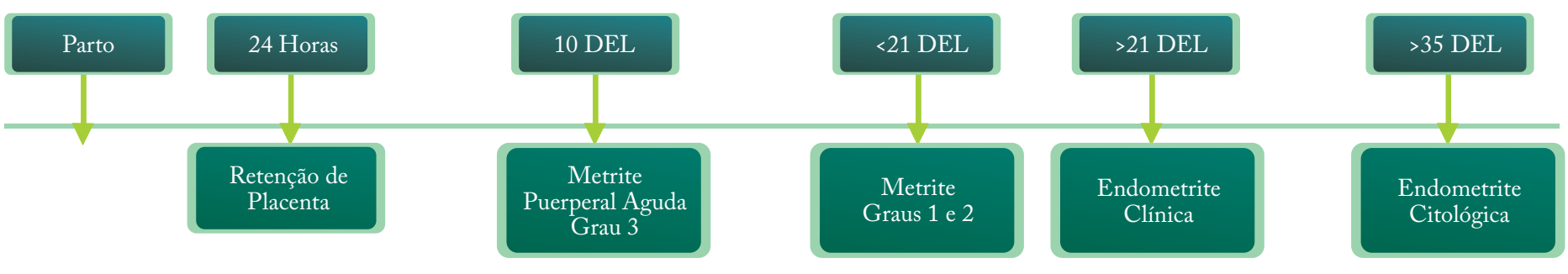

Figura 2. Ilustração da ordem cronológica de ocorrência de doenças uterinas no pós-parto de vacas leiteiras. 
to.

A metrite é a segunda doença e pode ocorrer até os $21 \mathrm{DEL}$, sendo mais comumente diagnosticada nos primeiros 10 DEL. A endometrite clínica, outra doença uterina que leva a grandes prejuízos nas propriedades leiteiras, é diagnosticada a partir dos 21 DEL. Por fim, a endometrite citológica ou subclínica ocorre após os 35 DEL e é considerada uma enfermidade de difícil diagnóstico pelos métodos tradicionalmente utilizados na avaliação do trato reprodutivo, dependendo de um exame complementar de citologia endometrial para o diagnóstico definitivo. A endometrite citológica pode chegar a $40 \%$ nos rebanhos leiteiros ${ }^{63-}$ 66,69

\section{- Retenção de placenta}

A retenção de placenta, também conhecida por retenção das membranas fetais, dos anexos fetais ou das secundinas, é definida pela falha na eliminação das membranas fetais no período de 24 horas após a expulsão do feto (Figura 3). A última das três fases do parto compreende a eliminação da placenta, que deve ocorrer o mais rápido após a expulsão fetal, no entanto, pode durar até 24 horas $^{10}$.

A incidência de retenção de placenta pode variar de 2 a $5 \%$ dentro de um rebanho leiteiro ${ }^{63}$, porém pode se tornar maior em casos de distocias, partos gemelares e na presença de agentes infecciosos ${ }^{63}$. Alguns estudos reportam incidências ainda maiores variando de $8,9 \%$ até $13,75 \%{ }^{70-73}$. Os principais fatores de risco para ocorrência de retenção de placenta são processos traumáticos, como distocias, parto de bezerros machos, grandes, gemelares e/ou natimortos, além do tempo de gestação anormal ou abortos. As doenças metabólicas, como a esteatose hepática, deficiência de algumas vitaminas, como vitaminas $\mathrm{E}$ e $\mathrm{A}$, e de minerais como cálcio e selênio estão relacionadas à ocorrência de retenção de placenta devido ao comprometimento do sistema imune das vacas. Além disso, infecções virais ou bacterianas do trato genital feminino, comprometem a maturação placentária, levando à placentite e, consequentemente, ao quadro de retenção de placen$\mathrm{ta}^{10,11,18,74,75}$.

Todos esses fatores de risco contribuem para a falha do sistema imune na eliminação da placenta,comprometendo principalmente a função dos neutrófilos, já que eles estão diretamente relacionados à eliminação
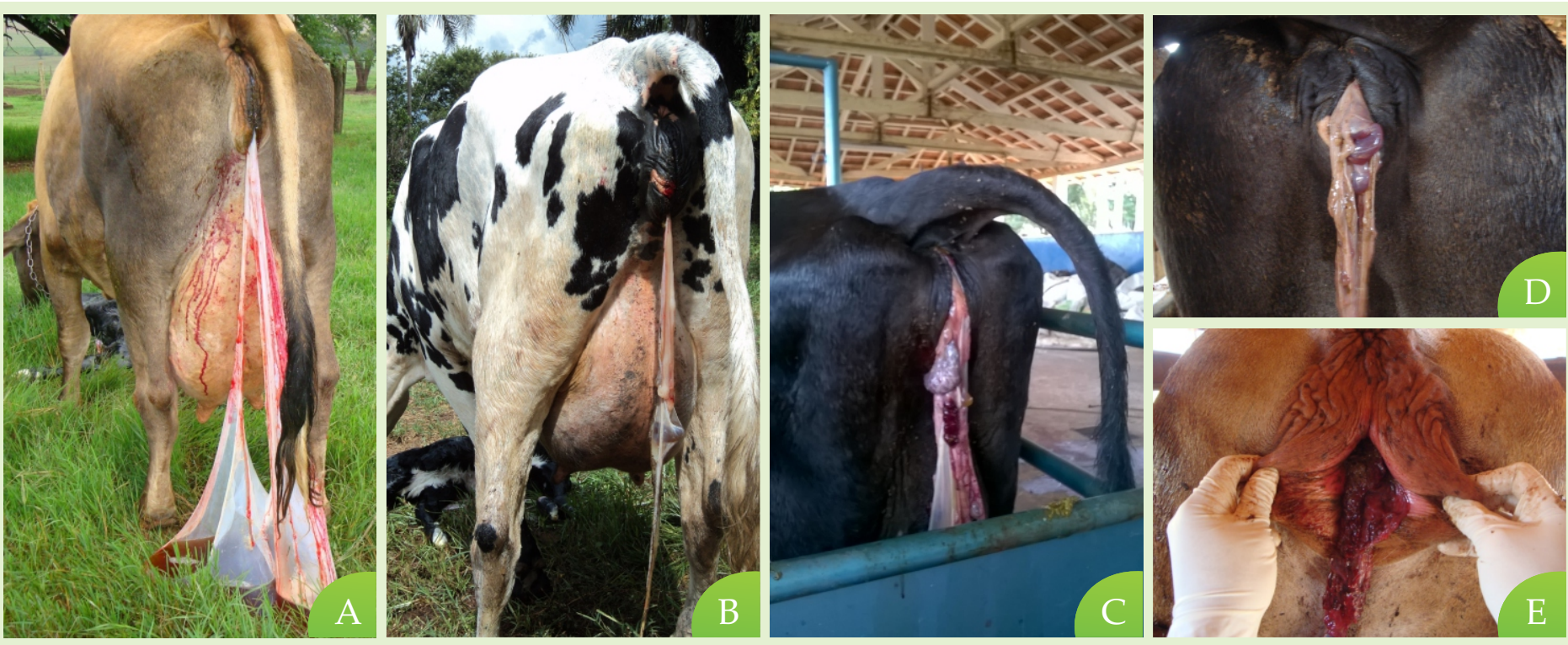

Figura 3. Quadros de liberação e retenção placentárias em bovinos. (A e B) Membranas fetais no pós-parto imediato e (C, D e E) retenção de placenta. 
da placenta, fagocitose dos dendritos, e participação na liberação dos grânulos citoplasmáticos que contêm algumas enzimas, dentre elas a colagenase, que irá auxiliar no processo de ruptura da adesão carúnculacotilédone ${ }^{32,76,77}$. Esta é a primeira manifestação de comprometimento do sistema imunológico, reflexo da exposição aos fatores de risco aqui relacionados e que aumenta em 6,25 vezes a chance destas vacas apresentarem metrite ${ }^{11}$. De acordo com Leblanc ${ }^{78}$ e Sheldon et al. ${ }^{59,64}, 30$ a $50 \%$ das vacas com retenção de placenta desenvolvem metrite.

\section{- Metrite}

A metrite acomete cerca de 25 a $40 \%$ das vacas nos rebanhos leiteiros e ocorre até os 21 DEL, principalmente nos primeiros $10 \mathrm{DEL}^{10}$. A metrite é a infecção uterina que acomete todas as camadas do útero e se caracteriza por aumento de volume uterino, repleto de conteúdo de coloração vermelho-amarronzado ou mucopurulento, com descarga uterina de odor fétido. A forma aguda de metrite ocorre nos primeiros $10 \mathrm{DEL} e$ é denominada metrite puerperal aguda ${ }^{79}$. A metrite é diagnosticada por meio do exame físico geral e especí- fico do trato genital feminino.

Esta doença uterina pode ser classificada em três diferentes graus. No diagnóstico de metrite grau 1, percebe-se um atraso na involução uterina, onde há um útero ainda aumentado e descarga uterina purulenta fétida, porém, sem qualquer sinal sistêmico. Já nos quadros de metrite grau 2, observa-se as mesmas alterações uterinas da metrite grau 1 , somadas à síndrome febre, apatia e redução na produção de leite. A forma mais grave da metrite (grau 3), envolve um quadro de toxemia, em que o animal encontra-se deprimido, em decúbito, anoréxico com desidratação grave (10 a 12\%), alterações cardiovasculares (aumento do tempo de preenchimento capilar e taquicardia) e respiratórias (taquipneia), extremidades frias, sendo necessária intervenção veterinária rápida e intensivista ${ }^{10,79}$ (Tabela 2$)$.

\section{- Endometrite}

A endometrite pode ser classificada em endometrite clínica e endometrite citológica ou subclínica. A endometrite clínica ocorre a partir dos 21 DEL e é caracterizada por descarga uterina purulenta aos 21 DEL ou mucopurulenta a partir dos 26 DEL.Já a endo-

Tabela 2. Classificação de metrite em bovinos em três diferentes graus, a partir das manifestações clínicas observadas.

Grau 1 Leve
Moderado
Aumento de volume uterino, descarga de secreção purulenta fétida e ausência de sinais sistêmicos.
Grau 3

Severo
Aumento de volume uterino, descarga de secreção purulenta fétida, com alguns sinais sistêmicos como queda na produção de leite e febre. 
metrite citológica (subclínica) não apresenta alterações macroscópicas, sendo diagnosticada por meio do exame de citologia endometrial, definida pela contagem de neutrófilos, quando essas células estão superiores a $18 \%$ entre 21 e 33 DEL, ou superiores a $10 \%$ entre 34 e 47 DEL $^{59,80}$.

\section{- Endometrite clínica e descarga vaginalpurulenta (DVP)}

A endometrite clínica, diferente da metrite, acomete apenas o útero das vacas sem a presença de alterações clínicas sistêmicas. Vale ressaltar que a presença da secreção mucopurulenta ou purulenta colhida na vagina pode ter sua origem tanto neste local (vaginite), quanto da cérvix (cervicite) e não necessariamente oriundo do lúmen uterino (endometrite clínica) ${ }^{81}$. Portanto, tem sido cada vez mais aceito a utilização do termo descarga vaginal purulenta (DVP) para caracterizar esta condição clínica, quando o diagnóstico é realizado somente pela avaliação das características da secreção coletada diretamente da vagina. Sabe-se que, independentemente da origem da secreção colhida, a DVP irá prejudicar o desempenho reprodutivo futuro do animal ${ }^{66,82}$.

A endometrite clínica representa 10 a 20\% do diagnóstico nas fazendas em relação à $\mathrm{DVP}^{83}$. O grande fator associado à doença é a colonização de bactérias, como Trueperella pyogenes, Fusobacterium necrophorum e Prevotella spp. ${ }^{10}$ no lúmen uterino. Quando o sistema imunológico não consegue ter uma resposta rápida e eficiente capaz de eliminar os agentes contaminantes do útero, há uma persistência da inflamação, que não se regula e conduz a esse quadro.

A DVP pode ser classificada em quatro diferentes graus ${ }^{79,84}$, como ilustrado na Figura 4.

Os exames complementares para avaliação da secreção vaginal podem ser feitos por meio da técnica da mão enluvada (Figura 5), espéculo vaginal ou Metricheck (instrumento formado por uma haste de metal com um coletor emborrachado em formato de copo na sua extremidade) (Figura 6).

Todos estes métodos irão colher a secreção vaginal, porém, a mão enluvada permite avaliação de lesões na mucosa, assim como o espéculo vaginal inspeciona sua coloração e o exame visual da cérvix. Já o Metricheck é considerado mais prático e de fácil higienização, porém permite apenas a avaliação da secreção, que pode ter origem tanto da vagina, quanto da cérvix ou do útero $^{64,85,86}$.

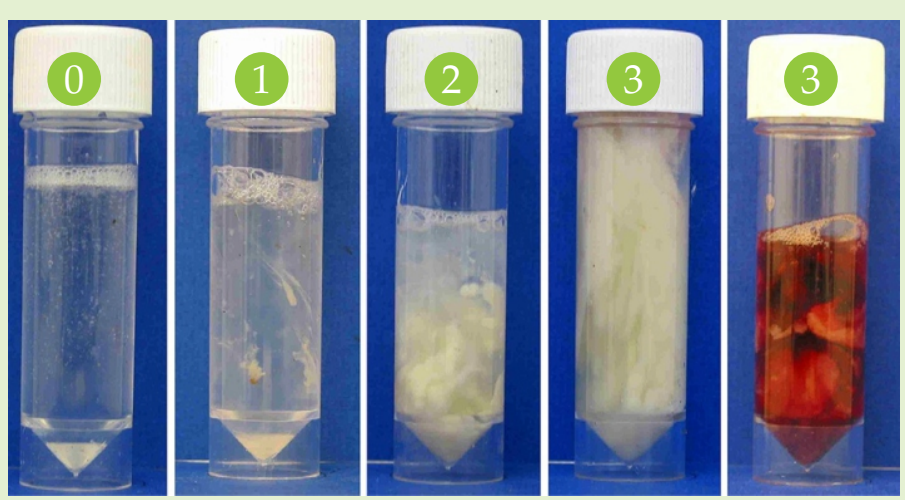

Figura 4. Classificação da descarga vaginal purulenta (DVP), em uma escala de 0 a 3. Grau 0: muco translúcido, Grau 1: presença de flocos de pus, Grau 2: secreção mucopurulenta com menos de 50\% de pus e Grau 3: secreção purulenta, com mais de $50 \%$ de pus (Fonte: Williams et al. $^{84}$ ).
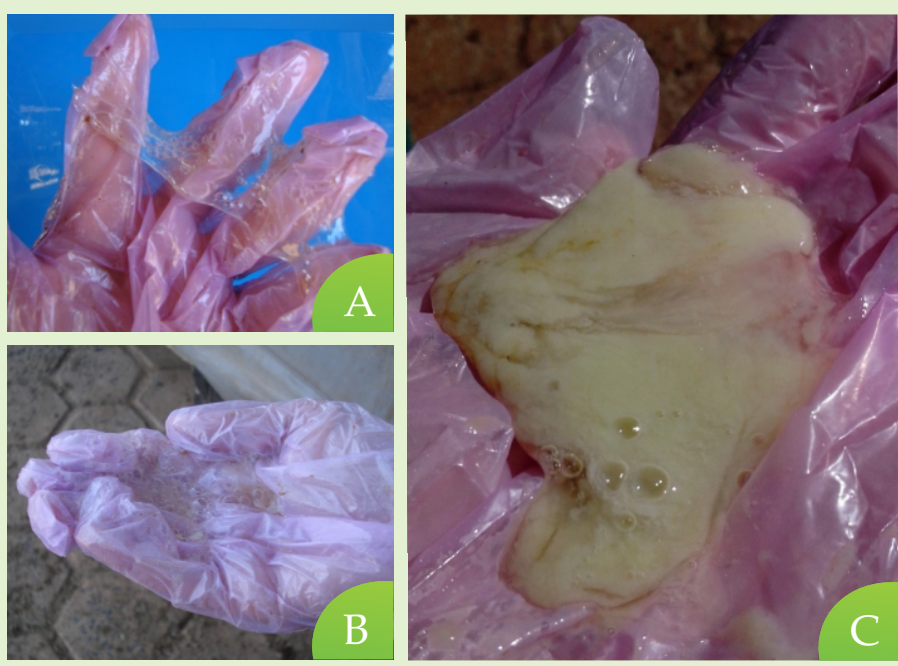

Figura 5. Diferentes graus de descarga vaginal purulenta (DVP), colhidas pela técnica de mão enluvada. (A) Grau 0,(B) grau 1 e (C) grau 3 

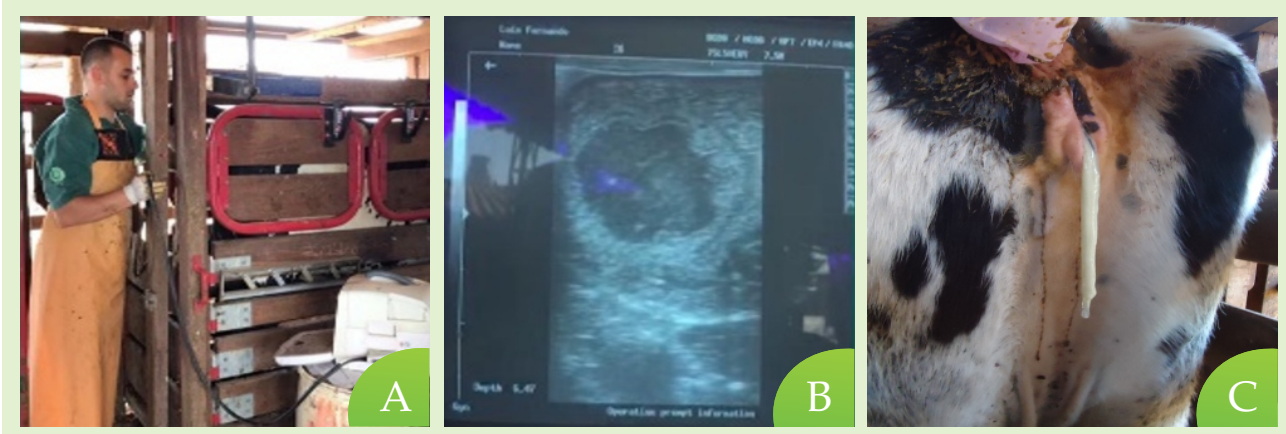

Figura 6.Diferentes métodos auxiliares de avaliação da descarga vaginal purulenta (DVP). (A) Palpação retal, (B) ultrassonografia, (C) inspeção da vulva, (D) espéculo vaginal, (E) Metricheck e (F) mão enluvada.
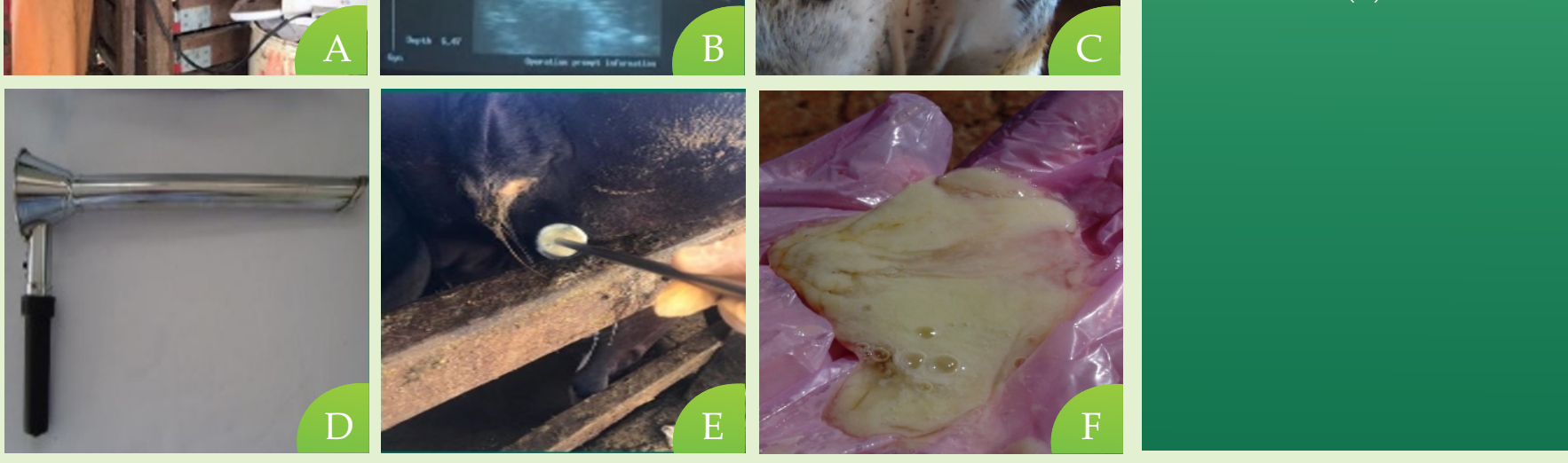

- Endometrite citológica ou subclínica

A endometrite citológica ou subclínica tem como característica a inflamação do endométrio com ausência de sinais clínicos, sendo detectada geralmente por citologia da superfície endometrial (Figura 7), pela contagem de células $\mathrm{PMN}^{64}$. A incidência desta enfermidade pode variar de 37 a $74 \%$ de acordo com o estudo realizado por Gilbert et al. ${ }^{87}$ e, segundo o mesmo autor, uma proporção maior ou igual a 5\% de PMN na citologia de animais com 40 a 60 DEL já é considerado quadro de endometrite citológica. Já para aqueles animais entre 21 e 33 DEL, segundo Kasimanickam et $\mathrm{al}^{88}$, a presença de endometrite citológica é caracterizada quando na citologia há mais que 18\% de PMN em relação ao total das células endometriais.

A manifestação de vacas com endometrite citológica se dá por meio das repetições de cio, conhecidas como repeat breeders, mas é uma situação em que os prejuízos já estão ocorrendo, aumentando o número de IA/concepção e os dias em aberto desses animais ${ }^{90}$. A persistência de agentes bacterianos no lúmen uterino pode ser uma das causas do desenvolvimento de endometrite citológica, ainda assim, a modulação do sistema imune pode estar comprometida nesse momento, havendo uma resposta mesmo na ausência de patógenos ${ }^{10}$. Os fatores de risco, mais uma vez, são traumas ao trato genital feminino, alterações metabólicas e a ocorrência prévia de doenças uterinas ${ }^{11,13,18,91}$.

A avaliação citológica pode ser realizada por meio de lavado uterino de baixo volume ou por meio da técnica de esfregaço endometrial, conhecida como técnica de cytobrush ${ }^{87,92}$ (Figura 8). A histologia endometrial, por meio da biopsia, traz ainda mais informações do processo inflamatório, no entanto, não é prático para o dia a dia das propriedades comerciais ${ }^{93,94}$.

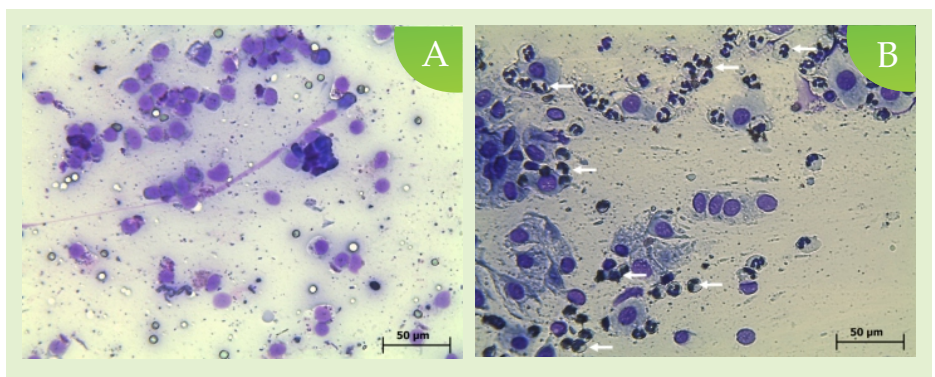

Figura 7. Avaliação citológica de amostras uterinas de vacas. (A) Sem endometrite citológica e (B) com endometrite citológica, apresentando elevada quantidade de células polimorfonucleares (setas), indicativo da reação inflamatória (Fonte: Fagundes et al. ${ }^{89}$ ). 

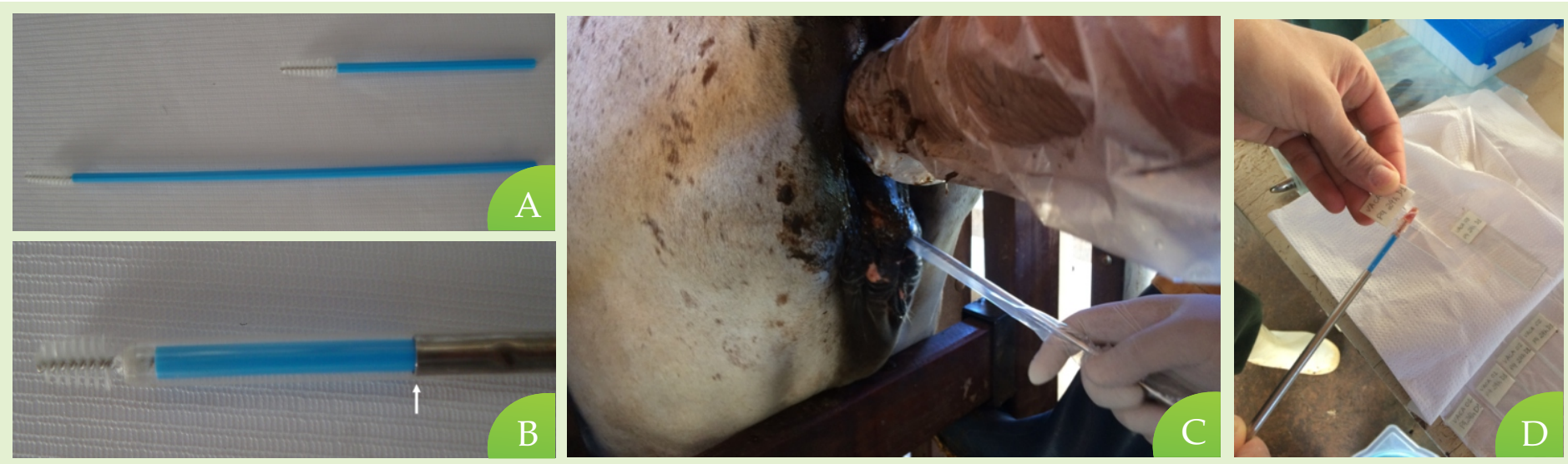

Figura 8. Técnica de esfregaço endometrial (cytobrush) utilizada no diagnóstico de endometrite citológica. (A) Redução da haste da escova citológica,(B) acoplamento da escova citológica no aplicador de sêmen (seta), protegida por bainha,(C) introdução transvaginal do aplicador no útero para coleta citológica e (D) esfregaço em lâmina para o exame citológico.

\section{COMPROMETIMENTO DA EFICIÊNCIA REPRODUTIVA}

A saúde da vaca leiteira durante o período de transição está diretamente ligada ao seu desempenho produtivo e reprodutivo ao longo da lactação. As doenças que geralmente as acometem neste período, especialmente aquelas do trato reprodutivo, influenciam negativamente a eficiência reprodutiva dos rebanhos, trazendo sérios prejuízos à cadeia produtiva do leite ${ }^{95}$.

Estudos que avaliaram os efeitos das doenças de maior prevalência no pós-parto sobre a fertilidade de vacas leiteiras demonstraram claras evidências de piora no desempenho reprodutivo como consequência das doenças, devido ao atraso no retorno à ciclicidade, redução da prenhez por inseminação artificial (P/IA) e aumento nas taxas de perda de gestação e de descarte dos animais ${ }^{60,73,96-100}$. É importante ressaltar que os prejuízos ligados à baixa eficiência reprodutiva dos rebanhos leiteiros não se restringem apenas às doenças que acometem diretamente o trato reprodutivo da fêmea, como a metrite e a endometrite, por exemplo. Sabe-se que, independentemente do local onde a infecção e a inflamação ocorrem, há um comprometimento sistêmico que atrapalha o funcionamento normal dos órgãos reprodutivos ${ }^{97,101}$.

Embora o impacto negativo das doenças do pós-parto no desempenho reprodutivo de vacas leiteiras já tenha sido demonstrado por diversos estudos, os mecanismos pelos quais os processos infecciosos e inflamatórios interferem direta e/ou indiretamente no funcionamento do trato reprodutivo ainda não foram totalmente elucidados ${ }^{97,102}$. Sabe-se que as respostas inflamatória e imunológica frente à infecção podem influenciar diversos processos reprodutivos tais como a dinâmica folicular ovariana e a esteroidogênese ${ }^{103-105}$, a ovulação $^{106,107}$, a competência ovocitária ${ }^{108}$, a fertilização ${ }^{97}$, o desenvolvimento embrionário ${ }^{97,109}$, a manutenção da gestação ${ }^{110,111}$, entre outros.

Um dos desafios à concepção logo após o fim do período voluntário de espera (PVE) é o prolongamento do anestro pós-parto. $\mathrm{O}$ anestro é definido como um período de inatividade sexual, isto é, sem manifestação de comportamento de estro, durante o qual ocorre a retomada da funcionalidade do eixo hipotálamo-hipófise-ovário-útero após a gestação anterior. As primeiras semanas pós-parto são necessárias para que ocorra a involução uterina, o reestabelecimento dos estoques dos hormônios reprodutivos e o reinício da atividade ovariana cíclica ${ }^{112}$. A ausência de um corpo lúteo (CL) e a baixa concentração plasmática de progesterona são características marcantes de vacas em anestro $^{113}$. Este período geralmente coincide com o PVE (30 a 50 dias), no qual as vacas não são cobertas ou 
inseminadas e sua duração varia de acordo com a decisão de manejo da fazenda, considerando o grupo racial e o nível de produção de leite dos animais.

O intervalo médio até o retorno da ciclicidade em vacas leiteiras é de $\pm 24 \mathrm{DEL}^{114}$, embora seja bastante comum identificar vacas que ainda não retomaram a ciclicidade aos $100 \mathrm{DEL}^{115}$. A ingestão limitada de energia, as baixas reservas corporais, o aumento no direcionamento de energia para a produção de leite e as doenças do periparto podem ser citadas como os principais fatores relacionados ao atraso no retorno à ciclicidade ovariana ${ }^{116}$. A lenta retomada da atividade ovariana no pós-parto é um grande impedimento para a inseminação das vacas imediatamente após o final do PVE, sendo assim uma limitação para o sucesso de programas de manejo reprodutivo ${ }^{116,117}$.

Os principais impactos das doenças uterinas sobre a lucratividade da atividade leiteira estão relacionados ao prolongamento do intervalo partoconcepção e ao descarte prematuro de vacas por estas não se tornarem gestantes durante a lactação $0^{63,98,118}$. Entre outros prejuízos associados à ocorrência de doenças uterinas, destaca-se a redução na ingestão de alimentos pelas vacas doentes que, consequentemente, leva à perda de escore de condição corporal (ECC) e consequentemente a uma considerável diminuição na produção de leite ${ }^{119}$. Esses prejuízos podem ser ainda maiores em fazendas leiteiras onde há alta incidência de infecções uterinas, considerando o aumento dos custos com medicamentos utilizados no tratamento das infecções, além do fato de que as doenças uterinas comprometem a saúde, o bem-estar e a produtividade das vacas acometidas ${ }^{64}$.

A perda de ECC e o BEN são os principais fatores relacionados à subfertilidade em vacas leiteiras $^{120}$. Praticamente todas as vacas sofrem algum grau de BEN no início da lactação ${ }^{121}$, sendo que a severidade e a duração do BEN podem ser estimadas pelas alterações no ECC das vacas ${ }^{122}$. Dobson et al. ${ }^{123}$ afirmaram que em rebanhos com baixo ECC ou com altas perdas de condição corporal, há uma drástica redução tanto na produção de leite quanto no desempenho reprodutivo em comparação aos rebanhos não afetados, uma vez que esse desequilíbrio nutricional atrasa a retomada da atividade ovariana, prejudica a expressão do estro e a concepção. Além disso, o BEN leva ao atraso no processo de involução uterina devido à supressão imunológica desse período ${ }^{124}$ e pode ser uma das causas da anovulação, já que o BEN proporciona uma condição hormonal inadequada ao desenvolvimento do folículo préovulatório, pico do hormônio luteinizante (LH) e ovulação ${ }^{120}$.

O atraso na ocorrência do estro seguido pela ovulação no pós-parto de vacas leiteiras está relacionado a retroalimentação negativa do estradiol (E2) sobre a liberação pulsátil do hormônio liberador de gonadotrofinas $(\mathrm{GnRH})$ pelo hipotálamo. $\mathrm{O}$ crescimento do folículo ovariano após a fase de seleção produz quantidades crescentes de E2, o qual inibe a liberação de GnRH e, consequentemente, do LH. Nesta fase, o crescimento deste folículo é dependente de LH e por isso não consegue atingir o diâmetro pré-ovulatório e a ovulação não ocorre. À medida que o BEN atinge a neutralidade ou se torna positivo, este efeito inibitório do E2 na secreção pulsátil de $\mathrm{GnRH}$ cessa, fazendo com que o folículo atinja o diâmetro pré-ovulatório e que a concentração de E2 seja suficiente para causar retroalimentação positiva na liberação de $\mathrm{GnRH}$ seguida pelo pico de LH, culminando com a primeira ovulação pós-parto $^{113}$.

Em estudo conduzido em uma fazenda localizada no estado de São Paulo, Monteiro et al. ${ }^{125}$ constataram que a ocorrência de um ou múltiplos episódios de doenças no pós-parto de vacas leiteiras Holandesas aumentou respectivamente em duas e três vezes o risco de as vacas apresentarem falhas na ovulação dentro dos primeiros 50 DEL. Mais especificamente, a retenção de placenta aumentou 2,7 vezes e a metrite 3,2 vezes o risco de anovulação em relação às vacas saudáveis. Estes resultados evidenciam que as doenças do pós-parto de 
vacas leiteiras predispõem ao atraso na retomada da atividade ovariana. Segundo Opsomer et al. ${ }^{126}$, a condição anovular de vacas leiteiras que adoeceram no pósparto é uma consequência de um severo BEN.

Em um estudo conduzido por Santos et al. ${ }^{127}$, foi avaliado os fatores de risco para o reestabelecimento da ciclicidade ovariana no pós-parto e para a sobrevivência embrionária, concluiu-se que o ECC ao parto e no momento da primeira IA pós-parto, assim como sua variação durante o pós-parto são fatores que influenciam o reinício da atividade ovariana avaliada aos 65 DEL, a taxa de concepção à primeira IA pós-parto e a sobrevivência embrionária avaliada aos 58 dias de gestação em vacas leiteiras Holandesas.

Middleton et al. ${ }^{128}$ demonstraram que $75 \%$ das vacas que ganharam ou mantiveram condição corporal nos primeiros $30 \mathrm{DEL}$ apresentaram intervalo parto-concepção menor que 130 dias. Neste estudo, também foi verificado que há uma relação significativa entre a perda de condição corporal nos primeiros 30 DEL e a chance de a vaca desenvolver pelo menos um quadro de doença clínica no pós-parto, já que as vacas que perderam ECC no início da lactação tiveram maior ocorrência de doenças em relação às que ganharam ou mantiveram condição corporal.

Estes resultados ajudam a explicar toda a cascata de eventos vivenciados pela vaca leiteira que adoece no pós-parto e tem seu desempenho reprodutivo comprometido. Uma vez doente, a vaca precisa primeiro se recuperar da doença clínica para depois conceber, embora já se saiba que os efeitos negativos das doenças se estendem mesmo após a resolução do quadro clínico ${ }^{99}$. Enquanto a concepção não acontece, a lactação avança, a produção de leite reduz de forma gradativa e a vaca ganha peso. Além disso, o período de serviço e o intervalo de partos se estendem. Quando chega o momento do próximo parto, essa vaca apresenta ECC elevado e no pós-parto ela perde condição corporal excessivamente, o que faz com que se torne mais propensa às doenças no pós-parto. Assim, fazer com que as vacas leiteiras apresentem ECC ideal ao parto, ou seja, não estarem excessivamente magras ou gordas (ECC moderado), e evitar grandes oscilações no ECC no início da lactação são alternativas para alcançar bons índices reprodutivos.

Foi demonstrado que a ocorrência de retenção de placenta promoveu atraso de dois a três dias até o primeiro serviço e de seis a doze dias na concepção, além de reduzir de 4 a 10\% a taxa de concepção ao primeiro serviço ${ }^{129}$. Em clima tropical, vacas leiteiras com retenção de placenta tiveram um período de serviço cerca de 27 dias mais longo do que vacas saudáveis ${ }^{73}$. Além disso, está enfermidade foi responsável pelo aumento da taxa de descarte, da duração do período de serviço e do número de inseminações requeridas por concepção ${ }^{98}$.

Já com relação à metrite, houve um atraso de sete dias até o primeiro serviço e de dezenove dias na concepção, e uma queda de $20 \%$ na P/IA ao primeiro serviço de vacas leiteiras ${ }^{129}$. Gilbert et al.$^{87}$ reportaram um aumento de 88 dias no período de serviço e uma redução de $26 \%$ na taxa de prenhez aos trezentos dias de lactação de vacas com endometrite clínica em relação às vacas sadias. A concepção ao primeiro serviço para vacas com endometrite clínica foi $25 \%$ menor do que para vacas saudáveis, além do fato das vacas acometidas necessitarem de mais serviços por concepção para se tornarem gestantes. Vacas Holandesas diagnosticadas com endometrite citológica não demonstram nenhum sinal aparente de doença uterina, mas sim um infiltrado de células inflamatórias no endométrio, que têm como consequência a redução na P/IA e prolongamento do período de serviço ${ }^{130,131}$. No entanto, a endometrite subclínica não compromete o desempenho reprodutivo de vacas leiteiras mestiças de menor produção ${ }^{98,132}$.

Um estudo desenvolvido por Carvalho et al. ${ }^{99}$ avaliou os efeitos a longo prazo das doenças clínicas ocorridas nos primeiros 21 DEL sobre o desempenho produtivo e reprodutivo de vacas leiteiras Holandesas. 
Como resultado, verificou-se que até os 305 DEL houve uma redução de 4\% na produção de leite e um aumento de $95 \%$ na taxa de descarte considerando vacas que tiveram pelo menos um episódio de doença clínica no fim do período de transição. Em relação ao desempenho reprodutivo, os autores reportaram 19\% de queda na taxa de prenhez e 31\% na taxa de parição, provavelmente porque os efeitos negativos causados pelas doenças do pós-parto afetam a manutenção da gestação mesmo após a recuperação clínica da doença.

A inflamação do endométrio de vacas que desenvolveram doenças uterinas no pós-parto parece ser o principal fator associado à perda de gestação em vacas leiteiras. Teoricamente, vacas submetidas à transferência de embriões (TE) não sofrem os efeitos negativos das doenças do pós-parto na expressão de estro, no desenvolvimento folicular e ovocitário, na fertilização e no desenvolvimento embrionário nos primeiros sete dias da mesma forma como acontece nas vacas inseminadas, já que parte destes eventos são realizados in vitro ou em outra vaca. No entanto, Edelhoff et al. ${ }^{110}$ observaram que vacas receptoras de embriões a fresco acometidas pelas doenças uterinas (retenção de placenta, metrite, endometrites clínica e citológica) tive- ram 33,9\% de perda de gestação à primeira TE após o parto, o que evidencia o comprometimento do ambiente uterino para que haja o desenvolvimento e a manutenção da gestação.

O número de casos de infecções uterinas que resultam em óbito é pouco relevante, porém há um aumento no risco de descarte de vacas acometidas pelas doenças uterinas devido ao seu baixo desempenho produtivo e reprodutivo ${ }^{98,119}$. De acordo com LeBlanc et al. ${ }^{133}$, há um aumento de 1,7 vezes no risco de descarte de vacas diagnosticadas com endometrite clínica entre os 20 e 33 DEL em relação às vacas livres de infecção.

O monitoramento periódico do trato reprodutivo das vacas na fase inicial do pós-parto é uma estratégia de manejo que permite diagnosticar e tratar precocemente os possíveis casos infecciosos, evitando assim maiores complicações do quadro clínico dos animais, porém, apesar da cura clínica, a eficiência reprodutiva não é recuperada ao longo da lactação. Os veterinários devem buscar implementar programas reprodutivos e de saúde bem elaborados, com foco na prevenção e que sejam capazes de manter no rebanho as vacas mais saudáveis e rentáveis.

\section{CONSIDERAÇÕES FINAIS}

Expomos, com esta revisão, as relações entre metabolismo, imunidade e fertilidade no periparto de vacas leiteiras, principalmente, no que tange às doenças uterinas e aos demais eventos que ocorrem no periparto, e que podem interferir na saúde e na fertilidade destes animais.

Ainda é necessário avançar na compreensão molecular das vias inflamatórias, que desempenham um papel importante durante a função imunológica "normal”, metabolismo e reprodução, para que possamos prever e prevenir alguns distúrbios do período de transição, compreendendo as disfunções do trato reprodutivo.

O acompanhamento periódico do trato reprodutivo das vacas auxilia nos diagnósticos e tratamento precoces e, ainda, o estabelecimento de métodos preventivos e de controle das doenças nesse período irão favorecer mais saúde, qualidade de vida e bem-estar ao rebanho e maior rentabilidade ao sistema produtivo. 


\section{AGRADECIMENTOS}

Os autores agradecem à Coordenação de Aperfeiçoamento de Pessoal de Nível Superior (CAPES) (Financiamento 001), à Fundação de Amparo à Pesquisa de Minas Gerais (FAPEMIG) (APQ00131-15; APQ-03740-16; APQ-01199-16), à Fundação de Amparo à Pesquisa de São Paulo (FAPESP) (2017/03622-3) e ao Conselho Nacional de Desenvolvimento Científico e Tecnológico ( $\mathrm{CNPq}$ ) (428442/2016-1) pelo apoio de recursos financeiros para execução de projetos e bolsas de estudo relacionados ao tema desta revisão.

\section{REFERÊNCIAS}

1. INGVARTSEN, K.L.; MOYES, K. Nutrition, immune function and health of dairy cattle. Animal, v.7, Supl.1,p.112-122,2013.

2. DRACKLEY,J.K. Biology of dairy cows during the transition period: the final frontier? Journal of Dairy Science,v.82,n.11,p.2259-2273,1999.

3. GRUMMER, R.R. Impact of changes in organic nutrient metabolism on feeding the transition dairy cow. Journal of Animal Science, v.73, n.1, p.2820-2833, 1995.

4. INGVARTSEN, K.L. et al. On the relationship between lactational performance and health: is it yield or metabolic imbalance that cause production diseases in dairy cattle? A position paper. Livestock Production Science, v.83,n.2-3, p.277-308,2003.

5. INGVARTSEN, K.L. Feeding- and managementrelated diseases in the transition cow: physiological adaptations around calving and strategies to reduce feeding-related diseases. Animal Feed Science and Technology,v.126,n.3-4,p.175-213,2006.
6. GOFF, J.P; HORST, R.L. Physiological changes at parturition and their relationship to metabolic disorders. Journal of Dairy Science, v.80, n.7, p.1260-1268, 1997.

7. SHELDON, I.M.; DOBSON, H. Postpartum uterine health in cattle. Animal Reproduction Science, v.82, n.82-83,p.295-306,2004.

8. LEBLANC, S.J. Reproductive tract inflammatory disease in postpartum dairy cows. Animal, v.8, Supl.1, p. 54-63,2014.

9. SHELDON, I.M. The postpartum uterus. Veterinary Clinics of North America: Food Animal Practices, v.20,n.3, p.569-591,2004.

10. SHELDON, I.M. The metritis complex in cattle. Veterinary Reproduction and Obstetetrics, v.1, n.1, p.408433,2018.

11.DUBUC, J. et al. Risk factors for postpartum uterine diseases in dairy cows. Journal of Dairy Science, v.93, n.12,p.5764-5771,2010.

12. PINEDO, P.J. et al. Innate immune gene variation and differential susceptibility to uterine diseases in Holstein cows. Theriogenology, v.80, n.4, p.384-390, 2013.

13. POTTER, T.J. et al. Risk factors for clinical endometritis in postpartum dairy cattle. Theriogenology, v.74, n.1,p.127-134,2010.

14. KIM, I.H.; KANG, H.G. Risk factors for postpartum endometritis and the effect of endometritis on reproductive performance in dairy cows in Korea.Journal of Reproduction and Development, v.49, n.6, p.485491,2003. 
15. CHAPINAL, N. et al. The association of serum metabolites with clinical disease during the transition period. Journal of Dairy Science, v.94, n.10, p.48974903,2011.

16. DAIBERT, E. et al. Metabolites able to predict uterine diseases in crossbred dairy cows during the transition period. Semina: Ciências Agrárias, v.39, n.3, p.1037-1047,2018.

17. BARRAGAN, A.A. et al. Assessment of daily activity patterns and biomarkers of pain, inflammation, and stress in lactating dairy cows diagnosed with clinical metritis. Journal of Dairy Science, v.101, n.9, p.82488258,2018 .

18. BRUUN, J. et al. Risk factors for metritis in Danish dairy cows. Preventive Veterinary Medicine, v.54, n.2, p.179-190,2002.

19. GALVÃO, K.N. et al. Symposium review: the uterine microbiome associated with the development of uterine disease in dairy cows. Journal of Dairy Science, v.102,n.12,p.11786-11797,2019.

20. ALBIGER, B. et al. Role of the innate immune system in host defence against bacterial infections: focus on the toll-like receptors. Journal of Internal Medicine,v.261, n.6, p.511-528,2007.

21. DAHA,M.R. Grand challenges in molecular innate immunity. Frontiers in Immunology, v.2, n.2, p.1-2, 2011.

22. SORDILLO, L.M. et al. Enhanced production of bovine tumor necrosis factor- $\alpha$ during the periparturient period. Veterinary Immunology and Immunopatho$\log y$, v.49, n.3, p.263-270, 1995.

23. BORO, P. et al. Alteration in peripheral blood con- centration of certain pro-inflammatory cytokines in cows developing retention of fetal membranes. Animal Reproduction Science,v.157,n.1,p.11-16,2015.

24. ZHANG, G. et al. Dairy cows affected by ketosis show alterations in innate immunity and lipid and carbohydrate metabolism during the dry off period and postpartum. Research in Veterinary Science, v.107, n.1, p.246-256,2016.

25. DERVISHI, E. et al. Alterations in innate immunity reactants and carbohydrate and lipid metabolism precede occurrence of metritis in transition dairy cows. Research in Veterinary Science, v.104, n.1,p.30-39, 2016.

\section{SURIYASATHAPORN, W. et al.}

Hydroxybutyrate levels in peripheral blood and ketone bodies supplemented in culture media affect the in vitro chemotaxis of bovine leukocytes. Veterinary Immunology and Immunopathology, v.68, n.2-4, p.177-186, 1999.

27. SORDILLO, L.M. et al. Immunobiology of the mammary gland. Journal of Dairy Science, v.80, n.8, p.1851-1865,1997.

28. PROTZER, U. et al. Living in the liver: hepatic infections. Nature Reviews Immunology, v.12, n.3, p.201-213,2012.

29. CECILIANI, F. et al. Acute phase proteins in ruminants. Journal of Proteomics, v.75, n.14, p.4207-4231, 2012.

30. GRUYS, E. et al. Acute phase reaction and acute phase proteins. Journal of Zhejiang University: Science, v.6B, n.11,p.1045-1056, 2005.

31. ECKERSALL,P.D.; BELL, R.Acute phase proteins: biomarkers of infection and inflammation in vete- 
rinary medicine. The Veterinary Journal, v.185, n.1, p.23-27,2010.

32. KIMURA, K. et al. Decreased neutrophil function as a cause of retained placenta in dairy cattle. Journal of Dairy Science, v.85, n.3, p.544-550,2002.

33. SINGH, J. et al. The immune status of the bovine uterus during the peripartum period. The Veterinary Journal,v.175,n.3,p.301-309,2008.

34. ESPOSITO, G. et al. Interactions between negative energy balance, metabolic diseases, uterine health and immune response in transition dairy cows. Animal Reproduction Science, v.144, n.3-4, p.60-71,2014.

35. BIONAZ, M. et al. Plasma paraoxonase, health, inflammatory conditions, and liver function in transition dairy cows. Journal of Dairy Science, v.90, n.4, p.1740-1750,2007.

36. BERTONI, G. et al. Effects of inflammatory conditions on liver activity in puerperium period and consequences for performance in dairy cows. Journal of Dairy Science, v.91,n.9, p.3300-3310,2008.

37. HUZZEY, J.M. et al. Short communication: haptoglobin as an early indicator of metritis. Journal of Dairy Science, v.92,n.2, p.621-625,2009.

38. TSAI, C.Y. et al. A rapid blood test to monitor the immune status change of dairy cows and to evaluate their disease risk during the periparturient period. Sensors Internacional,v.2,p.100078,2021.

39. GUNNINK, J.W. Pre-partum leucocytic activity and retained placenta. The Veterinary Quarterly, v.6, n.2, p.52-54, 1984.

40.MANN, S. et al. The degree of postpartum metabo- lic challenge in dairy cows is associated with peripheral blood mononuclear cell transcriptome changes of the innate immune system. Developmental and Comparative Immunology, v.93, p.28-36, 2019.

41. HAMMON, D.S. et al. Neutrophil function and energy status in Holstein cows with uterine health disorders. Veterinary Immunology and Immunopathology,v.113, n.1-2,p.21-29, 2006.

42. GOFF, J.P. The monitoring, prevention, and treatment of milk fever and subclinical hypocalcemia in dairy cows. The Veterinary Journal, v.176, n.1, p.50$57,2008$.

43. JÁNOSI, S. et al. Energy imbalance related predisposition to mastitis in group-fed high-producing postpartum dairy cows. Acta Veterinaria Hungarica, v.51, n.3,p.409-424,2003.

44. WATHES, D.C. Negative energy balance alters global gene expression and immune responses in the uterus of postpartum dairy cows. Physiological Genomics, v.39, n.1,p.1-13,2009.

45. DRACKLEY, J.K. et al. Major advances in fundamental dairy cattle nutrition. Journal of Dairy Science, v.89, n.4,p.1324-1336, 2006.

46. KOVÁČ, G. et al. Acute phase proteins and their relation to energy metabolites in dairy cows during the pre and post partal period. Acta Veterinaria Brno, v.78, n.3,p.441-447,2009.

47. ADEWUYI, A.A. et al. Non esterified fatty acids (NEFA) in dairy cattle. A review. Veterinary Quarterly, v.27,n.3,p.117-126, 2005.

48. LACETERA, N. et al. Short communication: effects of nonesterified fatty acids on lymphocyte 
function in dairy heifers. Journal of Dairy Science, v.87, n.4,p.1012-1014, 2004.

49. SCALIA, D. et al. In vitro effects of nonesterified fatty acids on bovine neutrophils oxidative burst and viability. Journal of Dairy Science, v.89, n.1, p.147-154, 2006.

50. LACETERA, N. et al. Lymphocyte functions in overconditioned cows around parturition. Journal of Dairy Science, v.88, n.6, p.2010-2016, 2005.

51. KLUCIŃSKI, W. et al. Effect of ketone bodies on the phagocytic activity of bovine milk macrophages and polymorphonuclear leukocytes. Zentralbl Veterinariarmed $A, \mathrm{v} .35$, n.8, p.632-639, 1998.

52. ERB,H.N.; GROHN,Y.T.Epidemiology of metabolic disorders in the periparturient dairy cow. Journal of Dairy Science, v.71, n.9, p.2557-2571, 1988.

53. GRÖHN, Y.T. et al. Epidemiology of metabolic disorders in dairy cattle: association among host characteristics, disease, and production. Journal of Dairy Science,v.72,n.7,p.1876-1885,1989.

54. CORREA, M.T. et al. Path analysis for seven postpartum disorders of Holstein cows. Journal of Dairy Science,v.76, n.5, p.1305-1312, 1993.

55. SORDILLO, L.M. Factors affecting mammary gland immunity and mastitis susceptibility. Livestock Production Science, v.98, n.1-2,p.89-99, 2005.

56. SPEARS, J.W.; WEISS, W.P. Role of antioxidants and trace elements in health and immunity of transition dairy cows. The Veterinary Journal, v.176, n.1, p.70$76,2008$.

57. MARTINEZ, N. et al. Evaluation of peripartal calcium status, energetic profile, and neutrophil function in dairy cows at low or high risk of developing uterine disease. Journal of Dairy Science, v.95, n.12, p.7158$7172,2012$.

58. ECKEL, E.F.; AMETAJ, B.N. Invited review: role of bacterial endotoxins in the etiopathogenesis of periparturient diseases of transition dairy cows. Journal of Dairy Science, v.99, n.8, p.5967-5990,2016.

59. SHELDON,I.M. et al. Tolerance and innate immunity shape the development of postpartum uterine disease and the impact of endometritis in dairy cattle. Annual Review Animal Bioscience, v.15, n.7, p.361-384, 2019.

60. SANTOS, J.E.P. et al. Applying nutrition and physiology to improve reproduction in dairy cattle. Society of Reproduction and Fertility Supplement, v.67, n.1,p.387-403,2010.

61. BRADFORD, B.J., et al. Invited review: Inflammation during the transition to lactation: new adventures with an old flame. Joutnal of Dairy Science, v.98, n.10,p.6631-6650, 2015.

62. RIBEIRO, E.S.; CARVALHO, M.R. Impact and mechanisms of inflammatory diseases on embryonic development and fertility in cattle. Animal Reproduction.v.14,n.3,p.589-600,2017.

63. SHELDON I.M. et al. Uterine diseases in cattle after parturition. The Veterinary Journal, v.176, n.1, p.115-121,2008.

64. SHELDON, I.M. et al. Defining postpartum uterine disease and the mechanisms of infection and immunity in the female reproductive tract in cattle. Biology of Reproduction, v.81,n.6,p.1025-1032, 2009.

65. LEBLANC, S.J. et al. Reproductive tract defense 
and disease in postpartum dairy cows. Theriogenology, v.76, n.9,p.1610-1618, 2011.

66. DEGUILLAUME, L. et al. Effect of endocervical inflammation on days to conception in dairy cows. Journal of Dairy Science, v.95, n.4,p.1776-1783, 2012.

67. ROBERTS, T. et al. Metabolic parameters in transition cows as indicators for early-lactation culling risk. Journal of Dairy Science, v.95, n.1, p.3057-3063,2012.

68. LEFEBVRE, R.C.; STOCK, A.E. Therapeutic efficiency of antibiotics and prostaglandin F2 alpha in postpartum dairy cows with clinical endometritis: an evidence-based evaluation. Veterinary Clinics of North America: Food Animal Practices, v.28, n.1, p.79-96, 2012.

69. LEBLANC, S.J. Alta produção de leite é compatível com boa reprodução? In: CURSO NOVOS E N F O QUE S N A P R O D UÇ Ã O E REPRODUÇÃO DE BOVINOS, 16, 2012, Uberlândia.Anais...Uberlândia:p.1-14,2012.

70. LAVEN, R.A.; PETERS, A.R. Bovine retained placenta: aetiology, pathogenesis and economic loss. Veterinary Record,v.139, n.19, p.465-471,1996.

71. NOBRE, M.M. et al. Evaluation of incidence rate and risk factors of retained placenta of crossbred dairy cattle. Arquivo Brasileiro de Medecina Veterinária e Zootecnia, v.64, n.1,p.101-107,2012.

72. FERNANDES, C.A. et al. Variação sazonal da incidência de retenção de placenta em rebanhos leiteiros no sul do Estado de Minas Gerais. Revista Brasileira de Ciência Veterinária,v.7,n.3,p.179-181,2000.

73. REZENDE, E.V. et al. Incidência da retenção de placenta e as consequências na produção de leite e na eficiência reprodutiva de vacas holandesas. Acta Scientiae Veterinaria,v.41,n.1,p.1170-1175,2013.

74. PAISLEY, L.G. et al. Mechanisms and therapy for retained fetal membranes and uterine infections of cows: a review. Theriogenology, v.25, n.3, p.353-381, 1986.

75. PINEDO, P. et al. Effect of oral calcium administration on the cure and reproductive performance of Holstein cows diagnosed with puerperal metritis. Journal of Dairy Science, v.100, n.4, p.2917-2927,2017.

76. HOEBEN, D. et al. Chemiluminescence of bovine polymorphonuclear leucocytes during the periparturient period and relation with metabolic markers and bovine pregnancy-associated glycoprotein. Journal of Dairy Research,v.67,n.2,p.249-259,2000.

77. RINALDI, M. et al. Differential alterations in the ability of bovine neutrophils to generate extracellular and intracellular reactive oxygen species during the periparturient period. The Veterinary Journal, v.178, n.2, p.208-213,2008.

78. LEBLANC, S.J. Postpartum uterine disease and dairy herd reproductive performance: a review. The Veterinary Journal,v.176, n.1,p.102-114,2008.

79. SHELDON, I.M. et al. Defining postpartum uterine disease in cattle. Theriogenology, v.65, n.8, p.1516-1530,2006.

80. DUBUC, J. et al. Effects of postpartum uterine diseases on milk production and culling in dairy cows. Journal of Dairy Science, v.94,n.3, p.1339-1346, 2011.

81. DUBUC, J. et al. Definitions and diagnosis of postpartum endometritis in dairy cows. Journal of Dairy Science, v.93, n.11, p.5225-5233,2010. 
82. AHMADI, M.R. et al. Comparative cervical cytology and conception rate in postpartum dairy cows. Veterinarski Arbiv,v.76, n.4,p.323-332,2006.

83. GERNAND, E. et al. Incidences of and genetic parameters for mastitis, claw disorders, and common health traits recorded in dairy cattle contract herds. Journal of Dairy Science, v.95, n.4, p.2144-2156,2012.

84. WILLIAMS, E.J. et al. Clinical evaluation of postpartum vaginal mucus reflects uterine bacterial infection and the immune response in cattle. Theriogenology, v.63, n.1,p.102-117, 2005.

85. DE BOER, M.W. et al. Invited review: Systematic review of diagnostic tests for reproductive-tract infection and inflammation in dairy cows. Journal of Dairy Science,v.97,n.7,p.3983-3999, 2014.

86. SANNMANN, I. et al. A critical evaluation of diagnostic methods used to identify dairy cows with acute post-partum metritis in the current literature. Journal of Dairy Research,v.79, n.4, p.436-444,2012.

87. GILBERT, R.O. et al. Prevalence of endometritis and its effects on reproductive performance of dairy cows. Theriogenology, v.64, n.9, p.1979-1888, 2005.

88. KASIMANICKAM, R. et al. Endometrial cytology and ultrasonography for the detection of subclinical endometritis in postpartum dairy cows. Theriogeno$\log y$, v.62, n.1-2,p.9-23,2004.

89. FAGUNDES, N.S. et al. Short communication: proinflammatory gene expression relative to the collection technique of endometrial samples from cows with and without subclinical endometritis. Journal of Dairy Science, v.102, n.6, p.5511-5517,2019.

90. KASIMANICKAM, R. et al. Mucin 1 and cytoki- nes mRNA in endometrium of dairy cows with postpartum uterine disease or repeat breeding. Theriogeno$\log y$, v.81, n.7, p.952-958, 2014.

91. LIMA, F.S. et al. Efficacy of ampicillin trihydrate or ceftiofur hydrochloride for treatment of metritis and subsequent fertility in dairy cows. Journal of Dairy Science, v.97,n.9, p.5401-5414,2014.

92. PASCOTTINI, O.B. et al. Comparison between cytology and histopathology to evaluate subclinical endometritis in dairy cows. Theriogenology, v.86, n.6, p.1550-1556,2016.

93. WAGENER, K. et al. A review of the ongoing discussion about definition, diagnosis and pathomechanism of subclinical endometritis in dairy cows. Theriogenology, v.94, n.1, p.21-30,2017.

94. MELCHER, Y. et al. Degree of variation and reproducibility of different methods for the diagnosis of subclinical endometritis. Theriogenology, v.82, n.1, p.57-63, 2014.

95. RAJALA, P.J.; GRÖHN, Y.T. Effects of dystocia, retained placenta, and metritis on milk yield in dairy cows. Journal of Dairy Science, v.81, n.12, p.3172-3181, 1998.

96. RIBEIRO, E.S. et al. Prevalence of periparturient diseases and effects on fertility of seasonally calving grazing dairy cows supplemented with concentrates. Journal of Dairy Science, v.96, n.9, p.5682-5697,2013.

97. RIBEIRO, E.S. et al. Carryover effect of postpartum inflammatory diseases on developmental biology and fertility in lactating dairy cows. Journal of Dairy Science,v.99, n.3, p.2201-2220,2016.

98. BUSO, R.R. et al. Retained placenta and subclini- 
cal endometritis: prevalence and relation with reproductive performance of crossbred dairy cows. Pesquisa Veterinária Brasileira,v.38, n.1,p.1-5,2018.

99. CARVALHO, M.R. et al. Long-term effects of postpartum clinical disease on milk production, reproduction, and culling of dairy cows. Journal of Dairy Science,v.102, n.12, p.11701-11717,2019.

100. CAMPOS, C.C. et al. Effects of clinical mastitis and puerperal diseases on reproductive efficiency of dairy cows. Tropical Animal Health Production, v.52, n.6,p.3061-3068,2020.

101. CAMPOS, C.C. et al. Intramammary infusion of lipopolysaccharide promotes inflammation and alters endometrial gene expression in lactating Holstein cows. Journal of Dairy Science, v.101, n.11, p.1044010455,2018.

102. BROMFIELD, J. et al. Mechanisms linking infection and innate immunity in the female genital tract with infertility in dairy cattle. Journal of Animal Science, v.93,p.2021-2033,2015.

103. HERATH, S. et al. Bacterial lipopolysaccharide induces an endocrine switch from prostaglandin $\mathrm{F} 2 \alpha$ to prostaglandin E2 in bovine endometrium. Endocrinology,v.150, n.4,p.1912-1920,2009.

104. MAGATA, F. et al. Lipopolysaccharide in ovarian follicular fluid influences the steroid production in large follicles of dairy cows. Animal Reproduction Science,v.144, n.1-2,p.6-13,2014.

105. PIERSANTI, R. et al. A model of clinical endometritis in Holstein heifers using pathogenic Escherichia coli and Trueperella pyogenes. Journal of Dairy Science,v.102,n.3,p.2686-2697,2019.
106. SUZUKI, C. et al. Endotoxin induces delayed ovulation following endocrine aberration during the proestrous phase in Holstein heifers. Domestic Animal Endocrinology,v.20,n.4,p.267-278,2001.

107. LAVON, Y. et al. Exposure to endotoxin during estrus alters the timing of ovulation and hormonal concentrations in cows. Theriogenology, v.70, n.6, p.956967,2008 .

108. ROTH, Z. et al. Naturally occurring mastitis disrupts developmental competence of bovine oocytes. Journal of Dairy Science, v.96, n.10, p.6499-6505,2013.

109. HANSEN, P.J. et al. Mastitis and fertility in cattle - Possible involvement of inflammation or immune activation in embryonic mortality. American Journal of Reproductive Immunology, v.51, n.4, p.294-301, 2004.

110. EDELHOFF, I.N.F. et al. Inflammatory diseases in dairy cows: risk factors and associations with pregnancy after embryo transfer. Journal of Dairy Science, v.103,n.12,p.11970-11987,2020.

111.MOLINA-COTO, R. et al. Ovarian function and the establishment and maintenance of pregnancy in dairy cows with and without evidence of postpartum uterine disease. Journal of Dairy Science, v.103, n.11, p.10715-10727,2020.

112. YAVAS, Y.; WALTON,J.S. Postpartum acyclicity suckled beef cows: a review. Theriogenology, v.54, n.1, p.25-55,2000.

113. WILTBANK, M.C. et al. Physiological classification of anovulatory conditions in cattle. Theriogenology, v.57,n.1,p.21-52,2002.

114. ROYAL, M. et al. Strategies for reversing the trend towards subfertility in dairy cattle. The Veterinary 
Journal,v.160, n.1,p.53-60,2000.

115. MANN, G.E. Problemas reprodutivos em vacas leiteiras - ciclicidade e estro. In: CURSO NOVOS E N F O QUE S N A P R O D U Ç Ã O E REPRODUÇÃO DE BOVINOS, 15, 2011, Uberlândia.Anais...Uberlândia,p.103-111,2011.

116. RHODES, F.M. et al. Invited review: Treatment of cows with an extended postpartum anestrous interval. Journal of Dairy Science, v.86, n.6, p.1876-1894, 2003.

117. THATCHER, W.W. et al. Strategies for improving fertility in the modern dairy cow. Theriogenology, v.65, n.1, p.30-44,2006.

118. BELL, M.J.; ROBERTS, D.J. The impact of uterine infection on a dairy cow's performance. Theriogenology,v.68,n.7,p.1074-1079,2007.

119. LEWIS, G.S. Uterine health and disorders. Journal of Dairy Science, v.80, n.5, p.984-994,1997.

120. LUCY MC. Mechanisms linking nutrition and reproduction in postpartum cows. Reproduction Supplement,v.61, n.1, p.415-427,2003.

121. LEBLANC SJ. Interactions of metabolism, inflammation, and reproductive tract health in the postpartum period in dairy cattle. Reproduction in Domestic Animals,v.47,Supl.5, p.18-30,2012.

122. BISINOTTO, R.S. et al. Influences of nutrition and metabolism on fertility of dairy cows. Animal Reproduction,v.9, n.3,p.260-272,2012.

123. DOBSON, H. et al. The high-producing dairy cow and its reproductive performance. Reproduction in Domestic Animals, v.42, Supl.2, p.17-23,2007.
124. WATHES, D.C. et al. Influence of negative energy balance on cyclicity and fertility in the high producing dairy cow. Theriogenology, v.68, Supl.1, p.232-241,2007.

125. MONTEIRO, P.L.J. et al. Prevalence and risk factors related to anovular phenotypes in dairy cows. Journal of Dairy Science, v.104, n.2,p.2369-2383, 2021.

126. OPSOMER, G. et al. Risk factors for post partum ovarian dysfunction in high producing dairy cows in Belgium: a field study. Theriogenology, v.53, n.1, p.841857,2000 .

127. SANTOS,J.E.P. et al. Risk factors for resumption of postpartum estrous cycles and embryonic survival in lactating dairy cows. Animal Reproduction Science, v.110,n.3-4,p.207-221,2009.

128. MIDDLETON, E.L. et al. The high-fertility cycle: how timely pregnancies in one lactation may lead to less body condition loss, fewer health issues, greater fertility, and reduced early pregnancy losses in the next lactation. Journal of Dairy Science, v.102, n.6, p.5577$5587,2019$.

129. FOURICHON, C. et al. Effect of disease on reproduction in the dairy cow: a meta-analysis. Theriogenology,v.53, n.9, p.1729-1759,2000.

130. GALVÃO, K.N. et al. Effect of prostaglandin F2 on subclinical endometritis and fertility in dairy cows. Journal of Dairy Science, v.92, n.10, p.4909-4913, 2009.

131. LIMA, F.S. et al. Effects of 1 or 2 treatments with prostaglandin $\mathrm{F} 2 \boldsymbol{\alpha}$ on subclinical endometritis and fertility in lactating dairy cows inseminated by timed artificial insemination. Journal of Dairy Science, v.96, n.10,p.6480-6488,2013. 
132. CARNEIRO, L.C. et al. Incidence of subclinical endometritis and its effects on reproductive performance of crossbred dairy cows. Tropical Animal Health and Production, v.46,n.8, p.1435-1439, 2014.

133. LEBLANC, S.J. et al. Defining and diagnosing postpartum clinical endometritis and its impact on reproductive performance in dairy cows. Journal of Dairy Science, v.85, n.9, p.2223-2236, 2002. 